\title{
Airway inflammation and inhaled corticosteroids in COPD
}

\author{
To the Editor:
}

We read with interest the recent article by Kunz et al. [1] in the European Respiratory Journal (ERJ), and the appropriately questioning accompanying editorial by CALVERLEY [2] in the same issue, considering airway inflammation and effects of inhaled corticosteroids (ICS) in chronic obstructive pulmonary disease (COPD). Understanding COPD pathology is a hugely important area and it is encouraging that leading respiratory journals are recognising this. We would like to suggest that a broader discussion of new insights into COPD pathology might have been appropriate. Thus, a more integrated consideration of overall airway wall cellularity, vascularity, epithelial-mesenchymal transition (EMT) and the effects of ICS on these in COPD is urgently needed to aid discussion of this devastating pathophysiology.

We have previously published that total airway wall cellularity is actually decreased in smokers and COPD patients [3]. This change is strongly associated with smoking history and tended to approach normal levels in ex-smokers with COPD. We ourselves initially found this surprising because it is at variance with the current "COPD-establishment" paradigm that the pathology is characterised by chronic inflammation in the airways, including the airway wall [3], but there are in fact few, if any, other reports on total airway wall cellularity in the literature. We subsequently found this to be a consistent result over some years of work and are in the process of publishing a confirmatory follow up study [4] indicating that both small and large airway walls in smokers and mild-moderate COPD patients were hypocellular.

Most of the studies in the COPD literature on this area do not seem to take into account total airway wall cellularity, which could have profound implications for the interpretation of differential cell counts. The GLUCOLD (Groningen and Leiden Universities Study of Corticosteroids in Obstructive Lung Disease) group have a strong and long-standing collective history of quantitative studies of airway biopsies. We wonder, therefore, whether L.I.Z. Kunz and colleagues have any information, either from their current study or cumulative experience, regarding this big-picture issue to help contextualise their findings? We also noted that their data seemed to indicate that the number of $\mathrm{CD}^{+}$cells in the airway wall outnumbered the $\mathrm{CD}^{+}$cell counts; this would be a finding that has not been shown before, to our knowledge, and is in marked contrast to our experience in COPD. We therefore wonder if the authors have any comment regarding their unusual $\mathrm{CD} 4^{+}$lymphocyte counts.

Active EMT and epithelial reticular basement membrane fragmentation and hypervascularity (with contrasting lamina propria hypovascularity) have also been shown to be present in the airway wall in COPD, and we have hypothesised that these changes represent fundamentally important aspects of COPD pathology [5,6] and may allow a unified understanding of important consequences of basal stem cell reprogramming. Insights into EMT and associated pathology in COPD may have the potential to be translated into a new paradigm for earlier therapy and improved clinical outcomes, and may contribute to the very active debates around ICS therapy in COPD. With respect to this, do L.I.Z. Kunz and colleagues have any information from their current study regarding ICS effects on EMT, airway wall vascularity or other manifestations of basal cell reprogramming?

We believe there is a need for debate and further in-depth studies of what are the fundamental issues with this disease; as CALverley [2] suggested, we have made some progress but need more. Even major published overviews of COPD largely ignore such important aspects of the disease as the realisation that $50 \%$ of small airways have been obliterated by airway remodelling before the forced expiratory volume in $1 \mathrm{~s}$ has even changed [7], and the lethal association between even early/mild COPD and lung cancer. It is biologically plausible that the link between cancer and COPD, which is an independent risk apart from

@ERSpublications

There is a need for in-depth discussion of new insights in COPD airway pathogenesis http://ow.ly/RDFM30bxduu

Cite this article as: Sohal SS, Eapen MS, Ward C, et al. Airway inflammation and inhaled corticosteroids in COPD. Eur Respir J 2017; 49: 1700289 [https://doi.org/10.1183/13993003.00289-2017]. 
smoking, may be related to parameters that could be more widely measured, such as markers of EMT or epithelial hypervascularity. Progression of this conversation will be helped by discussion of the different approaches by centres that have made great efforts to perform translational quantitative studies in COPD patient airways. We would be very interested in further debate, and indeed collaboration, between centres with access to and experience of working with human COPD tissue, in the spirit of the excellent article by DJUKANOvić et al. [8], published in the same issue of the ERJ. The leading respiratory journals have a key capacity to promote this approach through supporting novel descriptive human tissue studies that provide new insights and paradigms, even when at variance with the respiratory establishment's current "tenets".

Sukhwinder Singh Sohal ${ }^{1,2,4}$, Mathew Suji Eapen ${ }^{1,4}$, Chris Ward $\oplus^{1,3}$ and Eugene Haydn Walters ${ }^{1}$

${ }^{1}$ Breathe Well Centre of Research Excellence for Chronic Respiratory Disease and Lung Ageing, University of Tasmania, Hobart, Australia. ${ }^{2}$ School of Health Sciences, University of Tasmania, Launceston, Australia. ${ }^{3}$ Institute of Cellular Medicine, University of Newcastle Upon Tyne, Newcastle Upon Tyne, UK. ${ }^{4}$ These authors contributed equally.

Correspondence: Sukhwinder Singh Sohal, School of Health Sciences, University of Tasmania, Locked Bag - 1322, Newnham Drive, Launceston, Tasmania 7248, Australia. E-mail: sssohal@utas.edu.au

Received: Feb 092017 | Accepted after revision: March 022017

Support statement: This work was supported by the Clifford Craig Foundation. Funding information for this article has been deposited with the Crossref Funder Registry.

Conflict of interest: None declared

\title{
References
}

1 Kunz LIZ, ten Hacken NHT, Lapperre TS, et al. Airway inflammation in COPD after long-term withdrawal of inhaled corticosteroids. Eur Respir J 2017; 49: 1600839.

2 Calverley PMA. Through a glass darkly: inhaled corticosteroids, airway inflammation and COPD. Eur Respir J 2017; 49: 1602201.

3 Sohal SS, Reid D, Soltani A, et al. Changes in airway histone deacetylase2 in smokers and COPD with inhaled corticosteroids: a randomized controlled trial. PLoS One 2013; 8: e64833.

4 Eapen MS, McAlinden K, Tan D, et al. Profiling cellular and inflammatory changes in the airway wall of mild to moderate COPD. Respirology 2017 [https://doi.org/10.1111/resp.13021].

5 Soltani A, Walters EH, Reid DW, et al. Inhaled corticosteroid normalizes some but not all airway vascular remodeling in COPD. Int J Chron Obstruct Pulmon Dis 2016; 11: 2359-2367.

6 Sohal SS, Soltani A, Reid D, et al. A randomized controlled trial of inhaled corticosteroids (ICS) on markers of epithelial-mesenchymal transition (EMT) in large airway samples in COPD: an exploratory proof of concept study. Int J Chron Obstruct Pulmon Dis 2014; 9: 533-542.

7 Hogg JC, McDonough JE, Suzuki M. Small airway obstruction in COPD: new insights based on micro-CT imaging and MRI imaging. Chest 2013; 143: 1436-1443.

8 Djukanović R, Brusselle G, Walker S, et al. The era of research collaborations: new models for working together. Eur Respir J 2017; 49: 1601848.

Copyright @ERS 2017

\section{Airway inflammation in COPD after long-term withdrawal of inhaled corticosteroids}

\author{
From the authors:
}

We thank Dr Sohal and his colleagues for their correspondence regarding our recently published article in the European Respiratory Journal (ERJ) about airway inflammation in chronic obstructive pulmonary disease (COPD) after withdrawal of inhaled corticosteroids (ICS) [1]. We agree that COPD includes much more than airflow obstruction and airway inflammation alone and we would like to briefly respond to the issues raised in the correspondence.

The observation by Sohal et al. [2] that total airway wall cellularity is lower in smokers and COPD patients is interesting. In the GLUCOLD (Groningen and Leiden Universities Corticosteroids in Obstructive Lung Disease) study, we focused only on COPD patients and on changes in mucosal cell numbers for specific subsets of inflammatory and immune cells. Therefore, we cannot link our data to their conclusion on 
decreased cellularity in COPD. Sohal and colleagues also note that we detected higher numbers of CD $4^{+}$ $\mathrm{T}$-cells than $\mathrm{CD}^{+} \mathrm{T}$-cells and that this is in contrast to their findings. We have noted this difference in previous studies [3], as have other study groups [4-6] who have also described higher numbers of CD4 cells than CD8 cells in COPD. Furthermore, our data show good internal consistency during the various time points, which strengthens our results. It should be noted, however, that other studies have reported similar numbers of CD8 and CD4 cells $[7,8]$ while still more (including Sohal and colleagues) report higher numbers of CD8 cells than CD4 cells in the airway wall tissue of COPD patients $[9,10]$. These differences in the CD4/CD8 ratio in airway walls are therefore important to note and are likely to represent phenotypic heterogeneity amongst patients with COPD. It should be noted, however, that we cannot exclude an influence due to differences in immunohistochemical technique between these studies (such as the monoclonal antibodies used to quantify cell numbers). Sohal and colleagues also raise interesting and important questions regarding epithelial mesenchymal transition (EMT), vascularity and basal cell reprogramming in COPD. These are indeed important features of COPD that might be influenced by corticosteroid treatment. It is unfortunate that we do not have any data regarding these parameters.

We fully agree with Sohal and colleagues that collaboration between various centers is needed to address important issues regarding the pathology of COPD and its relationship to lung function and treatment response. This is indeed one of the reasons why the GLUCOLD study not only involves collaboration between various departments amongst the university medical centers of Groningen and Leiden in the Netherlands, but also includes contributions from other centers such as the pathology group of Thais Mauad at the University of São Paulo in Brazil. Indeed, larger international networks using standardised methodology are essential to shed further light on this important aspect of COPD research.

@ERSpublications

Detailed analysis of the effects of ICS on parameters beyond inflammation and lung function in COPD are needed http://ow.ly/mPN530c035q

Cite this article as: Kunz LIZ, ten Hacken NH, Lapperre TS, et al. Airway inflammation in COPD after long-term withdrawal of inhaled corticosteroids. Eur Respir J 2017; 49: 1700848 [https://doi.org/10.1183/ 13993003.00848-2017].

Lisette I.Z. Kunz ${ }^{1}$, Nick H. ten Hacken ${ }^{2}$, Thérèse S. Lapperre ${ }^{1,3}$, Wim Timens ${ }^{4}$, Huib A.M. Kerstjens ${ }^{2}$, Annemarie van Schadewijk ${ }^{1}$, Judith M. Vonk ${ }^{5}$, Jacob K. Sont ${ }^{6}$, Jiska B. Snoeck-Stroband ${ }^{6}$, Dirkje S. Postma ${ }^{2}$, Peter J. Sterk ${ }^{7}$, Pieter S. Hiemstra $\mathbb{1}^{1}$ and the GLUCOLD Study Group

${ }^{1}$ Dept of Pulmonology, Leiden University Medical Center, Leiden, The Netherlands. ${ }^{2}$ Dept of Pulmonary Medicine, University Medical Center Groningen, University of Groningen, Groningen, The Netherlands. ${ }^{3}$ Dept of Respiratory and Critical Care Medicine, Singapore General Hospital, Singapore, Singapore. ${ }^{4}$ Dept of Pathology, University Medical Center Groningen, University of Groningen, Groningen, The Netherlands. ${ }^{5}$ Dept of Epidemiology, University Medical Center Groningen, University of Groningen, Groningen, The Netherlands. ${ }^{6}$ Dept of Medical Decision Making, Leiden University Medical Center, Leiden, The Netherlands. ${ }^{7}$ Dept of Respiratory Medicine, Academic Medical Center, Amsterdam, The Netherlands. ${ }^{8}$ A full list of the GLUCOLD Study Group members and their affiliations can be found in the Acknowledgements section.

Correspondence: Lisette I.Z. Kunz, Dept of Pulmonology, Leiden University Medical Center, Albinusdreef 2, NL2333-ZA Leiden, The Netherlands. E-mail: L.I.Z.Kunz@lumc.nl

Received: April 232017 | Accepted: May 042017

Conflict of interest: Disclosures can be found alongside this article at erj.ersjournals.com

Acknowledements: The GLUCOLD study group consists of the following participants. H.F. Kauffman and D. de Reus (Dept of Allergology); H.M. Boezen, D.F. Jansen and J.M. Vonk (Dept of Epidemiology); M.D.W. Barentsen, W. Timens and M. Zeinstra-Smit (Dept of Pathology); A.J. Luteijn, T. van der Molen and G. ter Veen (Dept of General Practice); M.M.E. Gosman, N.H.T. ten Hacken, H.A.M. Kerstjens, M.S. van Maaren, D.S. Postma, C.A. Veltman, A. Verbokkem, I. Verhage and K. Klooster (Dept of Pulmonology; all University of Groningen and University Medical Center Groningen, Groningen, the Netherlands). H.A. Thiadens (Dept of General Practice); J.B. Snoeck-Stroband and J.K. Sont (Dept of Medical Decision Making); J. Gast-Strookman, P.S. Hiemstra, K. Janssen, K.F. Rabe, A. van Schadewijk, J.A. Schrumpf, J. Smit-Bakker, J. Stolk, A.C.J.A. Tiré, H. van der Veen, M.M.E. Wijffels and L.N.A. Willems (Dept of Pulmonology; all Leiden University Medical Center, Leiden, the Netherlands). P.J. Sterk (Dept of Respiratory Medicine, Academic Medical Centre, University of Amsterdam, Amsterdam, the Netherlands). T.S. Lapperre (Dept of Respiratory and Critical Care Medicine, Singapore General Hospital, Singapore, Singapore). T. Mauad (University of São Paulo, São Paulo, Brazil). 


\section{References}

1 Kunz LIZ, ten Hacken NHT, Lapperre TS, et al. Airway inflammation in COPD after long-term withdrawal of inhaled corticosteroids. Eur Respir J 2017; 49: 1600839.

2 Sohal SS, Reid D, Soltani A, et al. Changes in airway histone deacetylase2 in smokers and COPD with inhaled corticosteroids: a randomized controlled trial. PLoS One 2013; 8: e64833.

3 Lapperre TS, Snoeck-Stroband JB, Gosman MM, et al. Effect of fluticasone with and without salmeterol on pulmonary outcomes in chronic obstructive pulmonary disease: a randomized trial. Ann Intern Med 2009; 151: 517-527.

4 Fabbri LM, Romagnoli M, Corbetta L, et al. Differences in airway inflammation in patients with fixed airflow obstruction due to asthma or chronic obstructive pulmonary disease. Am J Respir Crit Care Med 2003; 167: $418-424$.

5 Verhoeven GT, Hegmans JPJJ, Mulder PGH, et al. Effects of fluticasone propionate in COPD patients with bronchial hyperresponsiveness. Thorax 2002; 57: 694-700.

6 Lams BE, Sousa AR, Rees PJ, et al. Immunopathology of the small-airway submucosa in smokers with and without chronic obstructive pulmonary disease. Am J Respir Crit Care Med 1998; 158: 1518-1523.

7 Saetta M, Di Stefano A, Turato G, et al. $\mathrm{CD}^{+}$T-lymphocytes in peripheral airways of smokers with chronic obstructive pulmonary disease. Am J Respir Crit Care Med 1998; 157: 822-826.

8 Turato G, Zuin R, Miniati M, et al. Airway inflammation in severe chronic obstructive pulmonary disease: relationship with lung function and radiologic emphysema. Am J Respir Crit Care Med 2002; 166: 105-110.

9 O'Shaughnessy TC, Ansari TW, Barnes NC, et al. Inflammation in bronchial biopsies of subjects with chronic bronchitis: inverse relationship of CD8+ T lymphocytes with FEV1. Am J Respir Crit Care Med 1997; 155: 852-857.

10 Fournier M, Lebargy F, Le Roy Ladurie F, et al. Intraepithelial T-lymphocyte subsets in the airways of normal subjects and of patients with chronic bronchitis. Am Rev Respir Dis 1989; 140: 737-742. 